А.Т. Сабиров ${ }^{*}$

Устная история как метод и источник в изучении местных сообществ (махалля). Опыт Узбекистана

DOI: $10.31518 / 2618-9100-2020-5-3$

УДК 930.2:352.075.2 (575.1) (043.3)

Выходные данные для цитирования:

Сабиров А.T. Устная история как метод и источник в изучении местных сообществ (махалля). Опыт Узбекистана // Исторический курьер. 2020. № 5 (13). С. 32-42. URL: http:// istkurier.ru/data/2020/ISTKURIER-2020-5-03.pdf
A.T. Sabirov ${ }^{*}$

\section{Oral History as a Method and Source in the Study of Local Communities (Mahalla). Uzbekistan's Experience}

\author{
DOI: 10.31518/2618-9100-2020-5-3
}

How to cite:

Sabirov A.T. Oral History as a Method and Source in the Study of Local Communities (Mahalla). Uzbekistan’s Experience // Historical Courier, 2020, No. 5 (13), pp. 32-42. [Available online:] http://istkurier.ru/data/2020/ISTKURIER2020-5-03.pdf

Abstract. This article reviews the experience of the Institute of History of the Academy of Sciences of Uzbekistan and a number of international organizations accredited in the country to conduct oral and historical research in Uzbekistan. According to the author, the experience of oral history in Uzbekistan is insufficient and is developing under the influence of the Russian historical science. This area is developing both in the social and academic aspects. At the same time, a series of challenges in the development of the new method were highlighted, such as fragmentation of research, weak methodological base, and lack of interaction between researchers. The process of institutionalizing the collection and analysis of oral memories based on specific projects and international cooperation is shown in stages. The theoretical courses for the development of oral history as a research method, followed by field and research practice, are described in detail. The article discusses specific methods of field research of local communities (mahalla) and small towns of Uzbekistan. The author notes specific challenges of conducting oral historical research, like official discourse in the memoirs of veterans, compliance with ethics in respect of researcher and respondent, language problems and others.

Keywords: Oral history; interviewing; historical memory; history and self-awareness; training; small towns; mahalla; biographical method; transcription.

The article has been received by the editor on 01.08.2020.

Full text of the article in Russian and references in English are available below.

Аннотация. В данной статье рассмотрен опыт Института истории Академии наук Узбекистана и ряда международных организаций, аккредитованных в республике по проведению устно-исторических исследований в Узбекистане. По мнению автора, опыт устной истории в Узбекистане недостаточен и развивается под влиянием российской исторической науки. Данное направление развивается как в социальном, так и академическом аспекте. При этом отмечен ряд проблем в развитии нового метода, таких как фрагментарность исследований, слабая методическая база, отсутствие взаимодействия между исследователями. Поэтапно показан процесс институционализации работы по сбору и анализу устных воспоминаний на базе конкретных проектов и международного сотрудничества. Подробно расписаны теоретические курсы освоения устной истории как метода исследований, которые сопровождались полевой и исследовательской практикой. В статье рассмотрены конкретные методы полевых исследований местных сообществ (махалля) и малых городов Узбекистана. Автор отмечает

\footnotetext{
* Сабиров Алишер Турсунович, кандидат исторических наук, Ташкентский государственный педагогический университет им. Низами, Ташкент, Узбекистан, e-mail: al sobir@inbox.ru

Sabirov Alisher T., Candidate of Historical Sciences, Tashkent State Pedagogical University named after Nizami, Tashkent, Republic of Uzbekistan, e-mail: al sobir@inbox.ru
} 
специфические проблемы проведения устно-исторических исследований: официальный дискурс в воспоминаниях ветеранов, соблюдение этики в отношении исследовательреспондент, проблема языка и др.

Ключевые слова: устная история; интервьюирование; историческая память; история и самосознание; тренинги; малые города; махалля; биографический метод; транскрибирование.

Несмотря на то, что у исследователей Центральной Азии постепенно растет интерес к методу устной истории, тем не менее опыт устно-исторических исследований пока очень скуден, и развивается в основном под влиянием российской научной школы, имеющей неплохой опыт устной истории ${ }^{1}$. Из интересных, новаторских работ можно отметить труд кыргызских исследователей по новейшей истории Кыргызстана, где авторы применили метод сравнения устных и письменных источников. ${ }^{2}$ В таджикской гуманитарной науке устная история через новый тип исторического исследования - «женская устная история» представлена в работах Б. Кабиловой и Н. Халимовой. ${ }^{3}$ Здесь же можно отметить монографию таджикистанской исследовательницы Л. Мягкой по устной истории русскоязычных женщин Таджикистана. ${ }^{4}$ Через устные рассказы русских женщин о своей жизни и жизни своей семьи исследователь осуществляла историческую фиксацию времени «мира социализма» и «коммунизма» как идеологии с позиции женщины в процессе ее движения. Проекты, связанные с женской устной историей, проводились в начале 2000-х гг. и в Кыргызстане. Итогом работ стала книга «Воспоминания женщин: устные истории переходного периода. Теория и практика» ${ }^{5}$, а также интересные наработки Э. Араповой из Ошского государственного университета ${ }^{6}$.

Интересен опыт устной истории в Казахстане, в т.ч. и как опыт международной группы исследователей в проекте «Депортация народов в Казахстан в 1930-1950 гг.: общность истории» ${ }^{7}$. Традиционно в Узбекистане в сфере устной истории работают этнографы. Особенностью узбекистанской этнографии всегда являлся ее историзм (в отличие от западной традиции, где этнологические исследования всегда были ближе к социологии). Однако узбекские историки использовали материалы устной истории (как источник) в своих исследованиях. Еще в начале 50-х гг. ХХ в., профессор Института истории АН Узбекистана $\mathrm{X}$. Зияев лично собрал воспоминания у оставшихся в живых участников национальноосвободительного восстания 1916 г. в Туркестане ${ }^{8}$. Практика сбора устных свидетельств активно стала использоваться с обретением Независимости Республикой Узбекистан, в основном как источник данных.

Специалистами Института истории АН Республики Узбекистан проводилось нарративное интервьюирование детей и других членов семьи участников антисоветских восстаний, репрессированных представителей узбекского дехканства, купцов, ремесленников, которые

\footnotetext{
${ }^{1}$ Ростовцев Е.A. Российская наука об устной истории // Вестник Санкт-Петербургского университета. История. 2018. Т. 63. Вып. 2. С. 522-545.

${ }^{2}$ Кокайсл П., Усманов А. История Кыргызстана глазами очевидцев (начало 20 века). Praha, 2012.

${ }^{3}$ Кабилова Б., Халимова Н. Устные истории женщин Таджикистана. Душанбе, 2003; Кабилова Б. Женские песни как устные истории // Современные проблемы гендерных исследований в Таджикистане. Душанбе, 2002.

${ }^{4}$ Мягкая Л. Жизнь как судьба, или Устные истории пожилых русскоязычных женщин Таджикистана. Душанбе, 2003.

${ }^{5}$ Воспоминания женщин: устные истории переходного периода. Теория и практика: сб. ст. Бишкек, 2001.

${ }^{6}$ Арапова Э. Невозможное возможно. Женские устные истории. Бишкек, 2005; Мещеркина Е. Качественные методы в гендерной социологии // Воспоминания женщин: устные истории переходного периода. Бишкек, 2001.

7 Депортация народов в Казахстан в 1930-1950 гг.: общность истории (интервью с пострадавшими от депортаций в 1930-50 годы в Казахстане). Астана, 2013.

${ }^{8}$ Сабиров А.Т. Устная история восстания 1916 г. в Ферганской долине // Восстания 1916 г. в Азиатской России: неизвестное об известном (К 100-летию Высочайшего повеления 25 июня 1916 г.). М., 2017. С. 481-485.
} 
были депортированы на Украину как социально опасные элементы ${ }^{9}$. Данные материалы стали систематизироваться и использоваться в экспозициях музея «Памяти жертв репрессий» Академии наук Республики Узбекистан ${ }^{10}$.

В свою очередь, работниками Музея «Памяти жертв репрессий проводились устноисторические исследования с представителями культуры, науки и духовенства Узбекистана, пережившими различные значимые события в истории своей страны, а также национальных диаспор, депортированных в Узбекистан. На основе глубинного интервью проводилась работа с представителями узбекской диаспоры в Турции, некогда бежавшими от репрессий из Узбекистана в 20-30-х гг. прошлого столетия, и интервьюирование родственников и учеников репрессированных ученых, живущих в Узбекистане, а также близких родственников бывших студентов германских вузов, отправленных учиться в 20-е годы прошлого столетия. Например, интервью с учеником профессора Тохир Чигатой Иброхимом Еркином и его сыном Санжар Еркином; академиком Елкин Туракуловым - учеником профессора С. Жаббарова (расстрелян в 1937 г.), а также его сыном Орхон Жаббаровым; племянницией выпускницы учительской семинарии г. Дармштадт Хайринисо Мажидхановой (расстреляна в 1937 г.) Холидой Кодировой; племянником выпускницы геологического факультета Берлинского университета Саиды Шерахмедовой Чингизом Акбаровым ${ }^{11}$. Интервьюирование органично сочеталось с исследованием анкетных данных. Были тщательно изучены специальные анкеты, которые заполнялись при поступлении на учебу в вузы Германии.

Специалисты музея выезжали в регионы Узбекистана, встречались с семьями репрессированных и собирали устный материал. Проводились на местах конференции, вечера памяти. Через радио и региональное телевидение люди узнавали о миссии музея и фонда «Шахидлар хотираси» (Память шахидов), приходили со своими материалами, делились своими воспоминаниями.

Специалист музея, кандидат искусствоведения С. Ахмедов, с использованием методов устной истории, проводил исследование с представителями культуры, науки и духовенства Узбекистана, тех людей, которые были репрессированы или депортированы за пределы Узбекистана, а также с респондентами, представляющими крымских татар, депортированных в Узбекистан. В процессе интервьюирования формировался банк данных по воспоминаниям репрессированных деятелей литературы и культуры ${ }^{12}$.

Отечественные исследования по устной истории ведутся в устно-исторических исследованиях. Следует отметить, что несмотря на определенные наработки по сбору и применению воспоминаний, в аспекте академической науки в Узбекистане ситуация с устно-историческими исследованиями характеризуется наличием определенных проблем. Основными из них являются:

- фрагментарность по сбору и анализу устных воспоминаний. Интересные исторические эпохи остаются вне поля зрения узбекистанских исследователей. Между тем представителей старшего поколения остается все меньше, и если не собрать их воспоминания сейчас, значительный пласт народной памяти окажется утраченным;

- отсутствие взаимодействия между различными группами исследователей;

\footnotetext{
${ }^{9}$ Зияев $X$. Ўзбекистон мустақилиги учун курашларнинг тарихи (История борьбы за независимость Узбекистана). Тошкент, 2001; Зияева Д. Босмачилик: Хақиқат ва уйдирма. (Басмачество: истина и мифы) Тошкент, 2002; Исмаилова Ж. Фарғона водийсидаги миллий озодлик курашлари (Национально-освободительное движение в Ферганской долине). Тошкент, 2003.

${ }^{10}$ Фонд видео- и аудиоматериалов Государственного музея Памяти жертв репрессий при КМ Республики Узбекистан.

${ }^{11}$ Сабиров А., Хасанов Б. Устная история как инновационный подход в музейном деле (на примере Государственного музея памяти жертв репрессий) // Устная история (Oral history) в отечественной и зарубежной практике: метод, источник, культурно-образовательные технологии: сб. ст. междунар. науч. конф. (1 ноября 2018 г., г. Ташкент). Ташкент, 2019. С. 28, 30.

12 Фонд видео- и аудиоматериалов Государственного музея Памяти жертв репрессий при КМ Республики Узбекистан.
} 
- слабая методическая база для проведения исследований в сфере устной истории (недостаток литературы, методических указаний, вопросников и пр.);

- недостаток опыта, знаний и средств.

Оптимальным средством преодоления этих проблем стала бы институционализация работы по сбору воспоминаний. В этом плане узбекистанским историкам попытались помочь немецкие международные организации, которые осуществляли свою деятельность на территории Узбекистана в начале 2000-х гг. Интересная работа по обмену опытом по методологии и методике устной истории была организована Представительством Института по международному сотрудничеству германской Ассоциации народных университетов (dvv international) в Узбекистане, в рамках проекта «История и самосознание». В данном проекте участвовали несколько немецких организаций: Представительство dvv international, Гёте-Институт Ташкент, Фонд им. Фридриха Эберта, Фонд им. Фридриха Науманна, Фонд им. Герды Хенкель, Германская Служба Академических Обменов (DAAD). Они провели несколько конференций, оказали поддержку в проведении семинаров по теме: «История и самосознание: местные особенности, программа и методы исследования», опубликовали серию книг по данной тематике.

Проект «История и самосознание» всегда опирался на принцип осознания истории через ее личностное восприятие очевидцами событий. К примеру, в 2009 г., в рамках этого проекта, была подготовлена и издана книга, посвященная воспоминаниям очевидцев Ташкентского землетрясения $1966 \Gamma .^{13} \mathrm{~B}$ этом процессе активно стал участвовать Институт истории АН Узбекистана, сформировав грамотную стратегию по реализации проектов по устной истории.

В 2010 г. через Фонд поддержки научно-исследовательских проектов выигран грант по реализации исследовательского проекта «Устная история Узбекистана XX в. как метод и источник исторического исследования» на 2010-2011 гг. Цель: Создание и институциональное развитие Центра “oral history” в Институте истории как учебно-методической базы для обучения специалистов и заинтересованных лиц новым методам истории на основе устной информации. Для более успешной реализации данной цели был разработан еще один, на этот раз совместный узбекско-германский проект под руководством автора статьи «Вызовы времени и устная история (развитие в Узбекистане новой исследовательской практики oral history - «устная история)» ${ }^{14}$, где были четко определены функции создаваемого в будущем научно-образовательного центра:

- координация работ по сбору воспоминаний;

- обеспечение технической поддержки;

- обеспечение методической поддержки;

- создание и хранение единой базы данных респондентов;

- создание и хранение фонотеки воспоминаний.

Особенность проекта заключалась в том, что теоретический курс освоения устной истории как метода сопровождался полевой и исследовательской практикой. Большое внимание уделялось принципам источниковедческого анализа интервью, а также сопоставлению устных источников с другими типами источников; важное место в программе занимало обучение современным технологиям записи, обработки и архивирования аудио- и видеоинформации.

Летом 2010 г. проводились тренинги для междисциплинарной команды г. Ташкента, включавшей в себя специалистов разных отраслей (историки, социологи, этнографы, лингвисты, архитекторы, режиссеры, журналисты). Причем сами тренинги были разделены на три этапа. Первые два этапа посвящены общей теме «Как использовать методы устной истории». Изучались такие вопросы, как «Ситуация интервью (схема, вопросы, темы)»,

\footnotetext{
${ }^{13}$ Ташкентское землетрясение 1966 года. Воспоминания очевидцев. Ташкент, 2008.

${ }^{14}$ См. Соглашение о сотрудничестве и совместной деятельности между представительством «Немецкой Ассоциации народных университетов (IIZ/DVV) и Институтом истории Академии наук Республики Узбекистан за 2010 и 2011 гг. // Текущий архив Центра устной истории Института истории АН РУз.
} 
«Метод наблюдения», «Социальные сети. История, теория, практика» и «Устная история. Семья как социальная память (методология)», «Методы распознавания достоверности источников информации», «Работа с техникой при проведении полевых исследований», «Создание гайдов» и т. д. Особое внимание уделялось теме «Психологические аспекты работы с респондентами» с участием опытного психолога.

Начальный этап работы oral history в Узбекистане стал очень полезным и неоценимым с точки зрения приобретения опыта для будущей работы с очевидцами истории, а методы проведения семинаров и дискуссий, с привлечением зарубежных специалистов, способствовали воспроизведению воспоминаний и работе с ними.

После получения теоретических навыков проводились практические занятия в формате пилотажного исследования на тему «Жизнь малых городов Узбекистана. Социокультурный аспект (вторая половина XX - начало XXI века)». Пилотаж проходил в регионах, имеющих древние земледельческие и ремесленные традиции: в трех областях Ферганской долины Наманганской (города Чуст и Туракурган), Андижанской (города Шахрихан, Асака), Ферганской (города Алтыарык и Кувасай). Тема пилотажа и указанные города выбирались самими участниками тренингов по социальным, экономическим, демографическим, этническим критериям.

Критерии разработанных гайдов были разделены на три уровня:

- микроуровень - биография личности, биография семьи;

- мезоуровень - биография махалли (местной общины);

- макроуровень - биография города.

Указанные вопросы раскрывались через традиции, образ жизни, быт, род занятий, архитектуру. Записи проводились с использованием цифрового диктофона, переносились на компьютер и на диск, который сохранялся, как и текстовая версия интервью. Методология этого направления предполагает хранение записей, для того чтобы исследователь мог воспользоваться для анализа не только смысловым и лингвистическим содержанием устного рассказа, но и эмоциональным фоном, сопутствующим трансляции (рассказу) человеком своего опыта. В результате участниками проекта получено более 30 аудиоинтервью, значительная часть которых к тому же зафиксирована в фото- и видеоформате, что послужило основой для архива Центра.

Осенью 2010 г. проводился завершающий этап тренинга, связанный с вопросами транскрибирования информации и последующего архивирования полученной информации, с участием российского эксперта М. Рожанского. Участники тренинга отрабатывали процедуры триангуляции на основе методов анализа интервью, включая расшифрованные интервью из числа полученных участниками проекта в процессе пилотажа.

На начальном этапе проекта было проведено очень любопытное исследование, в рамках научно-практического симпозиума «Архитектура между традициями и современностью». Симпозиум явился частью междисциплинарного проекта «Архитектура и идентичность», разработанного Гёте-институтом, DAAD, $d v v$ international в сотрудничестве с партнерскими организациями (Ташкентский архитектурно-строительный институт, Институт истории АН РУз и др.). В фокусе интересов симпозиума оказалась узбекская махалля как архитектурный и социальный объект. Немецкий исследователь М. Клингенберг отмечал: «Махалля является ядром традиционной узбекской культуры и в качестве низшей административной единицы городского управления относится в равной мере как к традиционной социальной реалии жизни узбеков, так и к политической структуре страны. С обретением независимости данная административная единица была перенесена и на части города, построенные в советский период. Однако под понятием “махалля” в общем понимается узбекский квартал, застроенный преимущественно одноэтажными домами в традиционном стиле» ${ }^{15}$.

\footnotetext{
${ }^{15}$ Клингенберг М. Махалля между традицией и современностью // История и Самосознание: опыт Узбекистана и Германии. Ташкент, 2006. С. 272.
} 
Жизнь в традиционных узбекских махаллях с учетом современных способов строительства жилья необходимо освещать с различных сторон: собственно архитектурной, исторической, этнографической, эстетической, культурологической. В центре особого внимания исследователей в настоящее время находятся историко-эстетические и архитектурные концепции жизни в «махалле будущего» и методы устной истории для выявления признаков, определяющих особенности самосознания. В рамках данного симпозиума прошли несколько мастер-классов по теме «Традиционная и современная архитектура узбекской махалли через Oral history», курировались со стороны $d v v$ international и были проведены под руководством автора статьи.

C помощью методики устной истории, которая нашла свое практическое применение в углубленных интервью с жителями махалли, мастер-классы предоставили эмпирический подход к исследованию процесса формирования и развития самосознания в махалле. Общей целью мастер-класса явилось изучение процесса трансформации облика махалли в контексте архитектуры, традиции, ментальности.

Цель своего практического исследования участники проекта сформулировали следующим образом: «Трансформация облика узбекской махалли (архитектура, традиции, ментальность)».

Мастер-класс состоял из трех этапов. Первый включал проведение обучающего тренинга по доступным методикам устно-исторического исследования в полевых условиях. Участниками тренинга были 25 человек - студенты, магистранты, аспиранты, молодые ученые архитекторы, историки, социологи, журналисты. Были рассмотрены такие аспекты проведения исследования методами Oral history, как составление интервью (его цели, задачи, вопросник и т.д.), психология поведения интервьюера и респондента, техника постановки вопросов, контроль памяти и т.д. Была четко сформулирована тема опроса: «Трансформация облика махалли: архитектура, традиции, ментальность». Основное внимание было уделено таким моментам, как: автобиография респондента; история семьи, дома, махалли в целом; особенности махалли (чем занимались и занимаются жители, в чем сходство и в чем отличия от соседних махаллей и т.д.); специфика архитектуры махалли; улицы, их история, названия, переименования; этнический и социальный состав населения махалли; знаменитости, проживающие (ранее проживавшие) в махалле или вышедшие из махалли; культовые постройки в махалле (если есть); общественные постройки (гузар, чайхана, тойхона и т.д.); инфраструктура (дороги, бытовые услуги и т.д.); характер озеленения и благоустройства территории; формы проведения традиционных мероприятий (свадьбы, юбилеи, праздники, варка сумаляка и т.д.); развитие и трансформация облика махалли; степень участия человека в делах махалли; предложения респондента по развитию облика махалли.

Рассматривались вопросы целей проведения исследования, социальная память, вклад Oral history в изучение традиционной и современной архитектуры узбекской махалли, поколенческий анализ, история семей. На основе обсуждения выделялись гипотетические факторы, влияющие на процесс архитектуры сквозь призму общины. Важным было и то, что модераторы остановились на психологических аспектах работы с респондентами. Главное в этом - искренний интерес интервьюера к респонденту, сопереживание рассказчику, организация условий психологического комфорта для него.

Разработка гайдов осуществлялась по следующим ключевым вопросам:

- досуг;

- наличие/отсутствие подсобного хозяйства;

- форма проведения традиционных мероприятий;

- моно/полиэтничность;

- форма управления;

- степень участия в делах общины;

- наличие собственности;

- выбор брачного партнера;

- степень автономности семьи и индивидуума; 
- характер потребления;

- элементы интеграции общины традиционной и современной;

- новые постройки, особняки, их роль и место в махалле.

Второй этап состоял из полевого исследования. Были выбраны две махалли г. Ташкента:

- махалля Сузук ота: (традиционная, моноэтническая - архитектура в форме индивидуальных домов с личными участками земли);

- махалля «Янги Камолон» (современная, полиэтническая архитектура в форме двухтрехэтажных особняков).

Методика проведения мастер-класса была направлена на максимальное получение навыков проведения устно-исторического исследования. Целевую группу - 18 студентов разделили на 6 мини-групп по 3 чел. K каждой группе прикреплялся 1 модератор. Было проведено 12 глубинных интервью с ветеранами махаллей в форме беседы. Беседы шли в соответствии с разработанной во время теоретической части мастер-класса схемой и касались таких тем, как: ощущение чувства общности, проведение досуга, форма проведения традиционных мероприятий, моно-/полиэтничность, степень автономности семьи и индивидуума, новые постройки и их роль в махалле и другие. Все это способствовало тому, что студенты на практике осваивали один из новых научных методов, учились правильно его использовать под руководством специалистов.

На третьем этапе полученный материал обсуждался, анализировался в группах и на заключительном пленарном заседании.

При активном участии разных специалистов (социологи, этнологи, архитекторы, историки, искусствоведы, журналисты) было проведено пилотажное сравнительное исследование в старой (традиционной) и новой (современной) махаллях Ташкента. Результаты исследования, проводимого в махаллях «Сузук-Ота» (традиционная) и «Янги Камолон» (современная) Шайхонтохурского района Ташкента показали, что традиционная и современная махалли сильно отличаются друг от друга не только по особенностям архитектуры, но и по специфике общественной жизни и быта, взаимоотношениям людей, мировоззрению членов махалли, социально-экономическому состоянию семьи, проведению обычаев и обрядов. Сравнительное изучение махаллей дало возможность наблюдать некоторые особенности узбекского менталитета. Например, и проживающий в многоэтажном доме экономист проф. Мухтор-ака Расулов, и житель традиционной махалли инженер Убайдуллахужа-ака были единогласны во мнении: «Так хорошо, если бы хоть клочок земли» ${ }^{16}$ (т.е. иметь бы двор, хотя бы маленький), - сказали они. Даже многие жители такого большого города, как Ташкент, думают, что жить лучше в доме со двором, чем в многоэтажном доме. Это обстоятельство показывает, что у узбеков до сих пор сильно сохраняются общественные взаимоотношения, взаимосвязи внутри махаллинской общины. Когда мы спросили информантов, почему они не хотят жить в благоустроенных квартирах, они ответили, что, «во дворе есть возможность общаться и установить близкий контакт со многими соседями и там удобно провести различные мероприятия» ${ }^{17}$.

Данное мини-исследование способствовало обучению участников способам воспроизведения воспоминаний и практической работы с ними, а также созданию определенного профессионального настроя.

Проведение ряда семинаров, тренингов и пилотажных исследований, участниками которых были разные слои населения Ташкента (учителя, вузовские работники, студенты, пенсионеры, ученые), осуществлялось с целью проблемно-тематического изучения самого метода, а также развития навыков работы с устной информацией. В результате сформировалась команда исследователей и волонтеров, работающих исключительно на основе использования метода устной истории. Научно-практическим результатом работы данной команды становится книга «Устная история в Узбекистане», которая включает публикации, посвя-

\footnotetext{
${ }^{16}$ Из интервью, взятых 21-22.10.2010 г. Б. Убайдуллаевой и Р. Назаровым // Текущий архив Института истории $\mathrm{AH} \mathrm{РУ}$.

17 Там же.
} 
щенные теоретическим вопросам и результатам практических исследований по устной истории Узбекистана и зарубежному опыту Oral history ${ }^{18}$.

Целью следующего этапа проекта (2011 г.) было распространение методов Oral history путем организации тренингов и практической работы среди научного, преподавательского, студенческого состава различных учреждений, общественных организаций и местных общин; приобщение общественности в регионах Узбекистана к изучению истории на микроуровне - через призму сознания реальных людей; содействие появлению сети центров устной истории; расширение архива устно-исторических материалов Института истории АН Узбекистана. В качестве пилотных объектов были выбраны сельские регионы древних историко-культурных центров Узбекистана - Бухары и Самарканда, а также проблемный экологический регион страны - Каракалпакстан.

Обучением методам устной истории в целевых объектах было охвачено 50 человек, на базе исторических факультетов Бухарского, Самаркандского государственных университетов и Института истории, этнографии и археологии Каракалпакского отделения АН РУз. Среди целевой группы - научные работники, преподаватели вузов, учителя школ и колледжей, аспиранты, студенты, музейные работники, активисты махаллей.

В программу тренингов входили вопросы методологии устной истории, социальная память и методы изучения семейной истории, работа с техникой при проведении полевых исследований, особенности проведения интервью, методы установления достоверности устно-исторической информации, создание гайдов, определение объектов и темы пилотажа. Структура тренингов включала обсуждение зарубежных статей по устной истории, анализ местного опыта устной истории, дискуссии, лекции, практические занятия.

Участники тренингов сами выбирали объекты для проведения пилотажного исследования (всего шесть малых городов в целевых регионах). Проводилась работа с респондентами от 23 до 65 лет. Социальный состав респондентов имел широкий спектр: рабочие, крестьяне, чиновники, интеллигенция. Путем обсуждения в малых группах в гайд включались ключевые вопросы:

- с какого времени живут в городе;

- что знают об истории города;

- детство и город;

- знаковые явления в жизни респондента, связанные с городом;

- изменения города, происшедшие на его глазах;

- образ жизни города сегодня (традиции, социальная сфера, экономика, педагогика, культура, образование);

- будущее города в понимании его жителя.

В результате данной работы в регионах Узбекистана были сформированы местные группы мотивированных специалистов ученых, преподавателей, музейных работников и студентов по проведению исследований по устной истории, накоплен и расширен архив устно-исторических материалов (72 интервью) и главное - процесс внедрения метода устной истории стал своеобразным мастер-классом для тех, кто решил изложить воспоминания прошлого.

При анализе полученных данных полевых исследований была выявлена характерная особенность, которая заключалась в том, что официальный дискурс более всего был представлен в воспоминаниях ветеранов, ранее не раз выступавших перед различными аудиториями, либо активных участников ветеранского движения. Их воспоминания более всего вписаны в национальную, государственную историю. Российская исследовательница Е.М. Стрекалова в процессе работы над проектом «30-40-е гг. в памяти ставропольцев» выявила аналогичную особенность: «Индивидуальные воспоминания у них спрессовались и были подменены неким идеальным, коллективным образом прошлого. И этот образ в их воспоминаниях, конечно, советский» ${ }^{19}$.

\footnotetext{
${ }^{18}$ Устная история в Узбекистане: Теория и практика. Ташкент, 2011. Вып. I.

${ }^{19}$ Стрекалова E.M. Память и забвение событий 30-40-х гг. по устным воспоминаниям ставропольцев [Электронный ресурс]. URL: http://www.newlocalhistory.com/node/860) (дата обращения: 05.12.2019).
} 
Мы столкнулись еще с одной проблемой. Это тема «исследователь и респондент». В основе устно-исторического исследования лежат в т.ч. биографические данные респондента (эксперта), владеющего ценными сведениями по традиционной культуре своего народа. Представители интеллигенции, как правило, люди не равнодушные к своей корневой культуре, хранители и трансляторы национальных традиций. Однако на контакт идут не сразу.

Также опыт наших полевых исследований показал, что беседы на родном языке с открытыми вопросами и свободными высказываниями позволили нам вывести исследование на качественно новый уровень. Речь идет о «социальной интимности полевых исследований» ${ }^{20}$. При этом респонденты вносили дополнительные ограничения для исследователя, желающего воспользоваться их свидетельством.

По нашему опыту в Фергане и Самарканде, иногда респонденты в начале беседы делали нам строгие указания. Наиболее распространенные среди них: «не обнародовать имя и фамилию рассказчика», «не раскрывать идентичность рассказчика», «не называть в публикациях собственных имен тех, кто упомянут в интервью», «мои воспоминания не делать достоянием широкой публики».

Полученный опыт устно-исторических исследований свидетельствует о том, что при использовании материалов устной истории требуется определенная осторожность. Личное восприятие человека субъективно, и факты могут быть искажены в силу политической, классовой, национальной и религиозной тенденциозности, слабой информированности и т.д. При этом они дают богатый материал для исследований по исторической антропологии, микроистории, истории ментальностей, истории повседневности, истории частной жизни, исторической психологии и других историко-антропологических направлений.

Еще один этап методологии устной истории - это наиболее затратная часть интервьюирования - транскрибирование и архивирование полевого материала.

Полученные в процессе тренингов навыки позволили сформировать группу по транскрипту и по разработанной инструкции проводить правильную фиксацию материала, включая стиль интервью, заметки исследователя, информацию о респонденте. В результате был сформирован архив устно-исторических материалов в аудио-/видеоформате и транскрибированной форме, который хранится в Институте истории АН Узбекистана.

С целью соответствия с установленными правилами архивации, были проведены дополнительные тренинги, на базе Национального архива кино-/фото-/фонодокументов Республики Узбекистан. Изучались методы материализации нематериальных объектов культурного наследия, технологии записи и хранения аудиовизуальной информации, оцифровка, архивация и форматы хранения устной информации, использование баз данных аудиовизуальных информационных ресурсов и массивов.

Пока еще небольшой узбекский опыт работы по устной истории приводит к пониманию необходимости рассмотрения устной истории как особой сферы научных исследований и как совокупности разнообразных путей и приемов анализа и интерпретаций собственно полученных с помощью интервьюирования текстов. Другими словами, актуальным на сегодня является акцентирование внимания на тех этапах устно-исторического исследования, которые начинаются уже после полевой работы, а именно на архивировании интервью, на стратегических подходах и методиках анализа, применяемых исследователями, что делает устную историю сугубо академической и одновременно открытой к публичному рассмотрению, дающей доступ к своим материалам представителям широкой общественности.

\footnotetext{
${ }^{20}$ Жамбалова С.Г. Реминисценции кочевого образа жизни на фоне повседневных практик советского и постсоветского времени (устная история Г.Б.Тудановой). Улан-Удэ, 2013. С. 10.
} 


\section{Лuтература}

Арапова Э. Невозможное возможно. Женские устные истории. Бишкек: [б.и], 2005. 120 с. Аскаров Ш. Махалля в эволюции города // Санъат. 2003. № 1. С. 12-16.

Воспоминания женщин: устные истории переходного периода. Теория и практика. Сборник статей. Бишкек: Женская сетевая программа ИОО, Женская программа Фонда Сорос-Кыргызстан. 2001. 332 с.

Депортация народов в Казахстан в 1930-1950 гг.: общность истории (интервью с пострадавшими от депортаций в 1930-50 годы в Казахстане) / под общ. ред. Б. Ракишевой. Астана, 2013. 683 с.

Жамбалова С.Г. Реминисценции кочевого образа жизни на фоне повседневных практик советского и постсоветского времени (устная история Г.Б. Тудановой) / отв. ред. Е.Н. Романова. Улан-Удэ: Изд-во БНЦ СО РАН, 2013. 147 с.

Кабилова Б. Женские песни как устные истории // Современные проблемы гендерных исследований в Таджикистане. Душанбе, 2002.

Кабилова Б., Халимова Н. Устные истории женщин Таджикистана. Душанбе: Ирфон, 2003. 305 с.

Клингенберг M. Махалля между традицией и современностью // История и Самосознание: опыт Узбекистана и Германии. Ташкент, 2006. С. 272.

Кокайсл П., Усманов А. История Кыргызстана глазами очевидцев (начало 20 века). Praha: Nostalgie, 2012. 280 c.

Мягкая Л. Жизнь как судьба, или Устные истории пожилых русскоязычных женщин Таджикистана. Душанбе, 2003.

Ростовцев Е.А. Российская наука об устной истории // Вестник Санкт-Петербургского университета. История. 2018. Т. 63. Вып. 2. С. 522-545.

Сабиров А.T. Устная история восстания 1916 г. в Ферганской долине // Восстания 1916 г. в Азиатской России: неизвестное об известном (K 100-летию Высочайшего повеления 25 июня 1916 г.): коллективная монография / ред.-сост. Т.В. Котюкова. М.: Русский импульс, 2017. С. 481-485.

Сабиров А., Хасанов Б. Устная история как инновационный подход в музейном деле (на примере Государственного музея памяти жертв репрессий) // Устная история (Oral history) в отечественной и зарубежной практике: метод, источник, культурно-образовательные технологии: сб. ст. междунар. науч. конф. (1 ноября 2018 г., г. Ташкент). Ташкент: Навруз. 2019. С. 28, 30.

Ташкентское землетрясение 1966 года. Воспоминания очевидцев / dvv-International. Ташкент, 2008. 243 с.

Устная история в Узбекистане: теория и практика: сб. мат-лов конф. / отв. ред. Р.М. Абдуллаев. Ташкент, 2011. Вып. І. 384 с.

\section{References}

Abdullaev, R.M. (Ed). (2011). Ustnaya istoriya v Uzbekistane: teoriya i praktika [Oral history in Uzbekistan: theory and practice]: sborn. mater. konf. [Collection of conference materials] / dvvInternational. Tashkent, Iss. I. 384 p.

Arapova, E. (2005). Nevozmozhnoe vozmozhno. Zhenskie ustnye istorii [The impossible is possible. Women's oral histories]. Bishkek, [s.n.]. 120 p.

Askarov, Sh. (2003). Makhallya v evolyutsii goroda [Mahalla in the evolution of the city]. In San'at. No. 1, pp. 12-16.

Kabilova, B. Zhenskie pesni kak ustnye istorii [Women's songs as oral stories] In Sovremennye problemy gendernykh issledovaniy v Tadzhikistane. Dushanbe, 2002.

Kabilova, B., Khalimova, N. (2003). Ustnye istorii zhenshhin Tadzhikistana [Oral histories of women in Tajikistan]. Dushanbe, Irfon. 305 p. 
Klingenberg, M. (2006). Makhallya mezhdu traditsiey i sovremennostyu (Mahalla between tradition and modernity. In Istoriya i Samosoznanie: Opyt Uzbekistana i Germanii [History and self-Awareness: the Experience of Uzbekistan and Germany]. Tashkent, p. 272.

Kokaysl, P., Usmanov, A. (2012). Istoriya Kyrgyzstana glazami ochevidtsev (nachalo 20 veka) [The history of Kyrgyzstan through the eyes of eyewitnesses (the beginning of the $20^{\text {th }}$ century]. Praha: Nostalgie. 280 p.

Myagkaya, L. (2003). Zhizn kak sudba, ili Ustnye istorii pozhilyh russkoyazychnyh zhenshchin Tadzhikistana [Life as Destiny, or Oral Stories of Elderly Russian-Speaking Women in Tajikistan]. Dushanbe.

Rakischeva, B. (Ed.) (2013). Deportatsiya narodov v Kazakhstan v 1930-1950 gg.: obshhnost istorii (intervyu s postradavshimi ot deportatsii v 1930-50 gody v Kazakhstane) [Deportation of peoples to Kazakhstan in 1930-1950: common history (interviews with victims of deportations in 1930-50 in Kazakhstan]. Astana. 683 p.

Rostovtsev, E.A. (2018). Rossiyskaya nauka ob ustnoy istorii [Russian science of oral history] In Bulletin of the Saint Petersburg University. History. Vol. 63. Vol. 2, pp. 522-545.

Sabirov, A., Khasanov, B. (2019). Ustnaya istoriya kak innovatsionniy podkhod v muzeynom dele (na primere Gosudarstvennogo muzeya pamyati zhertv repressiy) [Oral history as an innovative approach in the Museum business (on the example of the State Museum of memory of victims of repression]. In Ustnaya istoriya (oral history) $v$ otechestvennoy i zarubezhnoy praktike: metod, istochnik, kulturno-obrazovatelnye tekhnologii: sb. st. mezhdunar. nauch. Konf. (1 noyabrya $2018 \mathrm{~g}$. Tashkent) [Oral history in Russian and foreign practice: method, source, cultural and educational technologies: sat. scientific. conf. (November 1, 2018, Tashkent)]. Tashkent: Navruz, pp. 28, 30.

Sabirov, A.T. (2017). Ustnaya istoriya vosstaniya 1916 g. v Ferganskoy doline [Oral history of the 1916 uprising in the Ferghana valley]. In Vosstaniya $1916 \mathrm{~g} . v$ Aziatskoy Rossii: neizvestnoe ob izvestnom (K 100-letiyu Vysochayshego poveleniya 25 iyunya $1916 \mathrm{~g}$. [the 1916 Uprising in Asian Russia: the unknown about the known (For the 100th anniversary of the Supreme command on June 25, 1916]: kollektivnaya monografiya, T.V. Kotyukova (Ed.). Moscow, pp. 481-485.

(2008). Tashkentskoe zemletryasenie 1966 goda. Vospominaniya ochevidtsev [The Tashkent earthquake of 1966. The memories of witnesses] / dvv-International: Tashkent. 243 p.

(2001). Vospominaniya zhenshhin: ustnye istorii perekhodnogo perioda. Teoriya i praktika: Sbornik statey [Women's memories: oral histories of the transition period. Theory and practice. Collected papers]. Zhenskaya setevaya programma IOO, Zhenskaya programma Fonda SorosKyrgyzstan. 332 p.

Zhambalova, S.G. (2013). Reministsentsii kochevogo obraza zhizni na fone povsednevnykh praktik sovetskogo i postsovetskogo vremeni (ustnaya istoriya G.B. Tudanovoy) [Reminiscences of the nomadic way of life against the background of everyday practices of the Soviet and post-Soviet times (oral history of G.B. Tudanova)]. E.N. Romanova (Ed.). Ulan-Ude: BNTs SO RAN. 147 p. 